\title{
Potential of virtual worlds for marketing tests of product prototypes
}

\author{
João Varajão* and Leonel Morgado \\ Centro ALGORITMI/UTAD, Universidade de Trás-os-Montes e Alto Douro, Vila Real, Portugal; GECAD/UTAD, Universidade \\ de Trás-os-Montes e Alto Douro, Vila Real, Portugal
}

(Received 17 April 2011; final version received 7 November 2011)

\begin{abstract}
For manufacturers of physical goods, conducting market tests of product prototypes to assess consumers' preferences can be costly and complex. To some extent, production and logistic processes need to be in place, not just the marketing rationale. We put forth the hypothesis that virtual worlds may be a feasible environment to conduct early market tests of product prototypes for some physical products. The rationale for this hypothesis is that such tests with virtual versions of product prototypes may be conducted with minimal overhead, based on resources from marketing and design departments, without resources from production or logistics. They could be a first filter or selection process to determine which product prototypes demonstrate better acceptance by the public, with reduced costs and complexity. An expectation is that by having simpler and less costly tests, a wider variety of product prototypes can be considered, and test number and frequency increased, supporting better information gathering. A central question in this regard is the level of similarity between the preferences of the public when presented with virtual items, in comparison with the actual physical items. To attain data about this, we carried out an exploratory study, creating a set of both virtual and physical prototype versions of a physical product: t-shirts. We then invited virtual-world users to experience the virtual t-shirts on their avatars and express their preferences. Finally, we presented users with the option to buy the physical t-shirts with their own money, at promotional cost (as a reward for participating in the virtual trial), but explicitly told them, as they held the various physical versions in their hands, that they could change their preference at no extra cost. The results identified the level of similarity and differences between buyers' preferences in these two situations, pointing to the significant potential of using a virtual world to conduct market tests to assess consumers' preferences on prototypes of physical t-shirts.
\end{abstract}

Keywords: marketing tests; virtual world; virtual commerce; virtual business; Second Life

\section{Introduction}

In recent years, important changes happened in the way companies can present their products to the public. The evolution of computers and the day-to-day improved ability to make them communicate better have brought down information barriers, and raised new concepts of social interactivity (Rehmeyer, 2007).

Virtual worlds are part of this new reality, with particular emphasis for those that immerse users in quasireal three-dimensional (3D) environments, as they enable people to emulate part of their lives and routines in a virtual manner. This means one can experience aspects of real life, such as shopping, designing, chatting, working, while sitting at one's desk, behind a computer (Johnson, 2008). Studies indicate that presence, the sense of being within a virtual space, plays a strong role in psychological processes and on the personal significance of online events (Aas, 2011).
The economy is in constant evolution and commerce is no exception. While electronic commerce is not a novel concept, in recent years its growth has been considerable in terms of sales volume and public notice, with companies using the Internet not only for electronic sales transactions, but also to collect operational and market-related information.

Virtual worlds, such as Second Life ${ }^{\circledR}$, have brought forward a number of new business opportunities, due to the extended interactivity they allow not yet featured on normal web-based e-commerce sites. In a $3 \mathrm{D}$, multi-user virtual world, the physical consumer-product interaction can be mimicked, and many of the product characteristics may be tried and experienced by the potential costumer, and discussed with friends before buying, an experience closer to that occurring with the real-life virtual version of the product and real-life shopping.

\footnotetext{
*Corresponding author. Email: jvarajao@utad.pt
} 
This paper presents an exploratory work that aims to contribute to the study of emerging virtual worlds as marketing tools for businesses. Specifically, we wondered if the sense of presence and identity with virtual world avatars, and the parallels of shopping experiences between physical-world shopping and virtual-world shopping might render them useful to assess consumers' preferences for physical items, before actually manufacturing them. That is to say, we wondered whether virtual worlds could be a viable platform for less costly market tests of product prototypes of physical items, as a first-tier selection process of items to manufacture. By being less costly, such marketing tests could be deployed with a larger selection of prototypes, be repeated more often with variations of prototype details, and thus enable eventual market tests with the actual manufactured physical items to be conducted with better information on consumers' preferences of product prototypes and their features.

To evaluate the feasibility of this idea, a small business was created, with both virtual and physical versions of its products (t-shirts). A shop was created for this business in the Second Life (SL) virtual world, where buyers' preferences were evaluated. Buyers were subsequently offered the opportunity to buy the physical t-shirts in "real" life, at a discount price (for having expressed their preferences in the virtual world). To do so, they physically met the tshirt manufacturer and held all t-shirt versions in their hands, physically, before buying. They were told that the discount price applied to all t-shirts: they could choose the one they liked the most, it was not necessary to select the same they had selected online in the virtual world.

By matching consumers' preferences expressed online with their actual purchasing decisions when holding the physical items in their hands, we were able to compare buyers' preferences between physical and virtual versions of the products, assessing the potential of using a virtual world to test the feasibility of a product prototype.

The SL virtual world platform allowed us to build a virtual store to collect data. In this store, partially automated and open $24 \mathrm{~h}$ a day, we displayed posters with the virtual versions of the physical products ( $t$ shirts) being worn by avatars. Consumers were able to buy the virtual t-shirts and wear them in the virtual world at no cost, but with a small complication: they had to pay a minimum amount of game money (1 Linden dollar or L\$1, about USD 0.004), which was automatically returned to them after buying. This $\mathrm{L} \$ 1$ can be obtained either by buying Linden dollars with a credit card, by providing services to other virtual world users for cash, or by borrowing it from other users. The intent of this complication was to minimize the risk of having non-virtual world users register in the virtual world and take part in the test: since we were announcing it to the local academic community (in order to be able to approach them physically afterwards), some might wish to participate out of eagerness to be part of our test. Thus, given the L\$1 requirement, at least some prior experience and engagement with this virtual world was necessary, in order to possess or acquire the L\$1: people could not simply make a registration today in the virtual world and immediately head for the virtual shop and click on the preferred $\mathrm{t}$-shirt to express their preference. They had to have at least one Linden dollar.

We also produced physical equivalents of these virtual products, and conducted a market test with them, by approaching members of the academic community that had expressed their preferences in the SL store. They were presented by the manufacturer with the physical t-shirts equivalent to the virtual ones on display, held them in their hands and if they so desired they bought them with their own money (at a discount price). As mentioned previously, they were clearly told that the discount price was not solely for the t-shirt version they selected online: they could buy any of the presented t-shirts at the same price. In this way, we were able to analyse the choices made by the same individuals over the two media: in SL and physically.

That is, we expected to collect information about potential buyer's preferences about specific products, not only within the virtual platform, but also in the presence of the physical product. For this, we conducted two tests: a "virtual test", to collect participants" "buying preferences" on the virtual version of the product; and a "real-life test", to collect the participants buying preferences on the physical version of the product. We wondered whether the resulting datasets would be relatively coherent; if so, it would be a good indicator that companies could use virtual versions of t-shirts as a first approach to analysing their feasibility as physical products - a more readily usable and cost-effective way to make operational marketing decisions.

This idea has been echoed in various media outlets (e.g. by prototyping new products in a virtual world including engineered products even before they are created, a firm can save time and money and garner richer and more accurate feedback - Thilmany, 2008), but we have so far not seen hard data in support of it. We believe our efforts may help understand whether a virtual world such as SL can be seen as valid commercial opinion indicator, not only regarding sales volume, but also on the reliability level a virtual product preference vis-à-vis its physical version. 
In the section "Background", we present the background, introducing SL potential as an entrepreneurship tool. The research method is discussed in the "Method" section. In the section "Prototype and experiment", the created prototype and the conducted experiment are presented. Then, in the section "Results and discussion", we discuss the obtained results. Finally, in the section "Conclusion and further work", some final remarks are made and paths for further work are suggested.

\section{Background}

SL is a well-known virtual world, whose use has grown considerably between 2006 and 2009, not only in number of users, but also in capabilities and features for development of customized solutions (Gorini, Gaggioli, Vigna, \& Riva, 2008), and has since plateaued at about 580,000 regular monthly users, with an average 50,000 users being simultaneously online in SL (Nino, 2011). Commercial activity is already well present in SL, and many companies already use it not only as a sales branch, but also as a place where commercial information can be gathered (Thilmany, 2008).

It can be defined not only as a virtual world to visit, but as a virtual platform, since its contents are created by and for its users, using a variety of free tools for graphical modeling and texturing, animation definition and even programming scripts for interactions and interfacing with external information systems (e.g. Valério et al., 2009). Almost every aspect of real life that is possible to emulate virtually, has been developed in this platform by its users. Even the social behaviour within this platform has been reported as very close to the real world:

Second Life may be an online Utopia, but its social politics look awfully familiar. (Bans, 2008)

Second Life is one of the most popular online metaverses (a fancy term for virtual worlds). Visitors to the site create avatars - virtual 'people' - to represent themselves and their computer screen becomes a window to a virtual world. (Benetton, 2007)

... think of it like a cross between a video game and a virtual reality simulation of the real world. Through their avatars, people can journey through online environments that resemble fictitious lands as well as actual places, with roads, buildings, islands and so forth. But Second Life isn't only an interesting place to visit - it offers potentially interesting business opportunities as well. (Benetton, 2007)

SL has been used in the recent past as a tool for entrepreneurship (Stewart, 2007), and its economic figures indicate USD 1,500,000 spent in user-to-user transactions yearly (Nino, 2011). Large companies established their presence within SL (Scott, 2007) often made not with instant profit in mind, but with the intention to improve their brand image. Only a few established companies actually employ SL as a sales channel, with individuals representing the majority of entrepreneurial activity in this platform.

A virtual product is not a mere representation or token of a physical item; it has value in itself, but typically people are wary to pay relatively high prices for something that they cannot really "own". "Smart marketers will imagine their brands not as they are in the real world, but as they fit within this free-form play space" (Au, 2008). One must wonder, however, if this reluctance will not diminish as virtual ownership of products, even outside virtual worlds, increases (e-books and music files subscription models where only a few of the purchased items are stored locally, for instance).

Companies like American Apparel and Reebok have a positive corporate presence with boutiques where they can not only make a little money but also promote the brands to Second Life residents who might then be more inclined to be consumers offline too. Other corporations doing interesting things in Second Life include: Starwood Hotels' loft-style hotel bar where you can hang out; Sun Microsystems presentation space where they work with their gaming developers; TextlOO, a public relations firm that conducts live press conferences for clients in Second Life; and Toyota, which sells cars for your avatar to motor around in. In my opinion, all are useful and interesting ways to have a corporate presence that shouldn't be dismissed as exploitative. (Scott, 2007)

Thus, SL proves itself useful as a communication channel, where the relation between the potential client and the brand can benefit. There is also prototyping potential within SL, and this could be used to garner operational information relative to products and marketing tests of product prototypes.

\section{Method}

In order to analyse the differences and similarities in buyers' preferences between the virtual and the physical world, our first step was to define which product to test. Such a product should be feasible to produce in both virtual and physical versions, both usable autonomously, within a reasonable budget, and both versions should be recognizable as similar by potential buyers.

We opted to develop t-shirts as our first test product. The choice for this type of product was a combination of two circumstances: they are a product with a low cost of physical manufacture (particularly given our academy's geographical proximity to one of 
Portugal's main textile industry areas) and also a common product in the active e-commerce activity of SL, where various kinds of apparel and clothing in general are a commonly traded item, with numerous shops available (Neustaedter \& Fedorovskaya, 2009).

Since our objective was to obtain feedback from the public about product prototype preferences as a source of information for subsequent production of physical versions, we defined the following development process:

(1) Create a new brand for this purpose.

(2) Design three different t-shirt models with a specific brand (see Figure 1).

(3) Manufacture the physical t-shirts.

(4) Construct a virtual shop in SL (Figure 2).

(5) Program virtual shop sales terminals to log data for every transaction.

(6) Ask several people to "buy" (in effect, at zero cost, as explained in the introduction) their preferred virtual t-shirt model (collecting data about buyers' preferences of virtual products) (Figure 3).

(7) Sell the physical t-shirts to roughly the same users that had expressed their virtual preferences (collecting data about buyers' preferences of physical product), giving them full freedom of choice and no influence on choice.

(8) Data analysis, comparing the two sets of results.

Ideally, each individual participating in the test with virtual products should also participate in the test with physical products, allowing us to analyse differences related solely to the virtual/physical nature of the product and the individuals' relationship with them, not to differences in the user sample. To achieve this, we invited people to visit the virtual shop, rather than simply wait for consumers to arrive haphazardly. They visited the shop first, and provided their preference. It was only a few days later that the physical t-shirts were presented to each of these people, to see whether they would be interested in buying the physical item - and which version.
The shop in SL was at the following location (since abandoned, for our academy moved from the "Utopia Portugal VI" region to its own region, "UTAD"): http://slurl.com/secondlife/Utopia\%20Portugal $\% 20 \mathrm{VI} / 55 / 48 / 31$.

\section{Prototype and experiment}

Construction in SL is based on object assembly, and many of the objects' parameters can be defined by the user, such as shape, colour, texture, etc. Further, objects may possess executable computer code - also known as scripts.

The virtual store for this experiment was built in $\mathrm{SL}$, and the created t-shirt models were identical in shape and design, but had differing colours: black, brown and white. Each board visible in Figure 3 would provide a t-shirt to the avatar upon payment of L $\$ 1$ (one Linden Dollar, the currency used in SL, as mentioned in the introduction), but that $\mathrm{L} \$ 1$ would be returned to the avatar immediately afterwards - hence we stated that it was a selection, not a purchase. As explained in the introduction section, this paymentand-return complication meant that at least minimal prior experience with SL was required to take part in the test.

The boards were coded with a script (Figure 4), to report on a user's payment, i.e. a t-shirt selection event. Specifically, every time an avatar selected her/ his t-shirt an e-mail was sent to a POP3 email account created for this purpose, containing the avatar's name, the avatar's key (unique identifier), the chosen item and the date and time of the selection (Figure 5).

In this selection process, only the first pick of each avatar was considered. Thus, if an avatar chose to get a copy of all three t-shirt models, we considered the first choice to be the preferred one. The full process is presented in Figure 6.

After selecting a product in the virtual store, the buyer was entitled to buy the physical product, by personally contacting the researchers. When s/he would do so, the buyer would have the option to choose again amongst the three t-shirt models (black, white
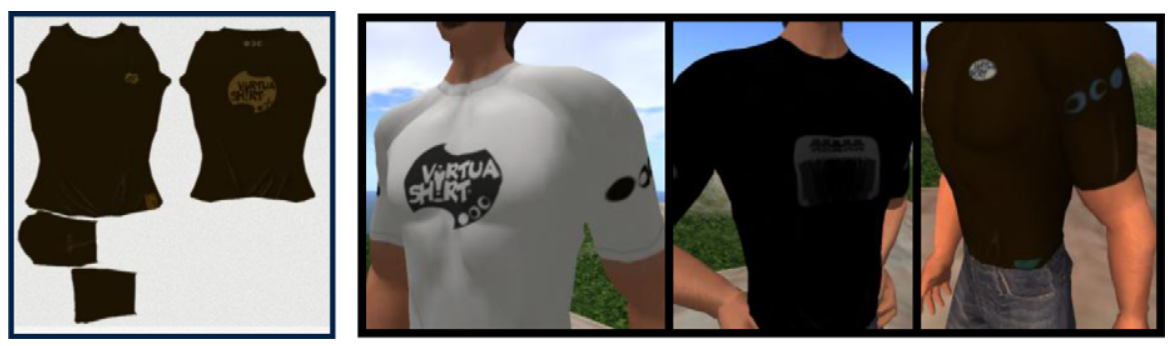

Figure 1. T-shirt model and virtual versions. 


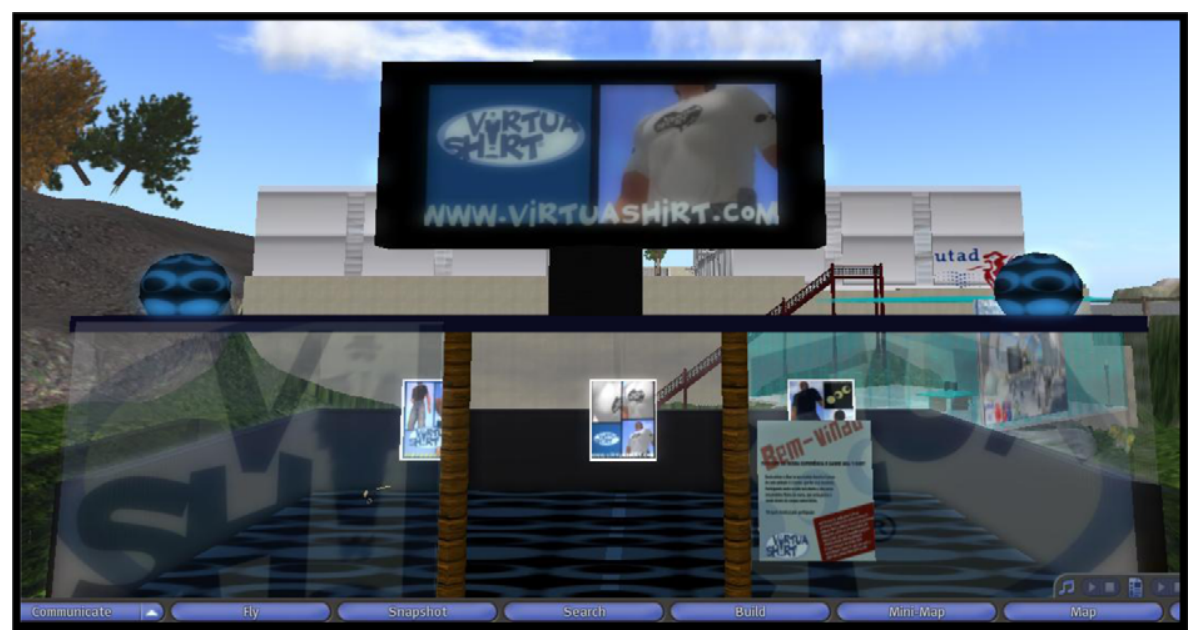

Figure 2. Outside look of the virtual shop.
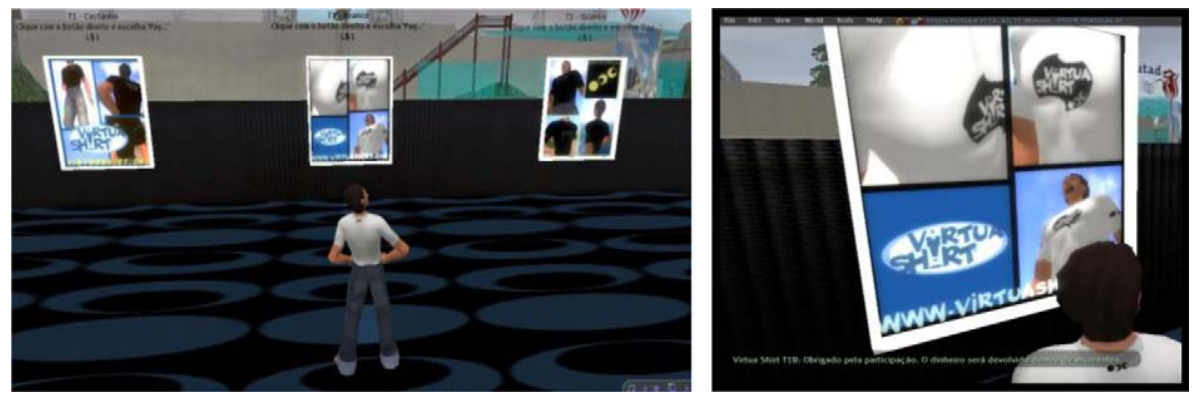

Figure 3. An avatar inside the virtual shop, when confronted with the virtual models.

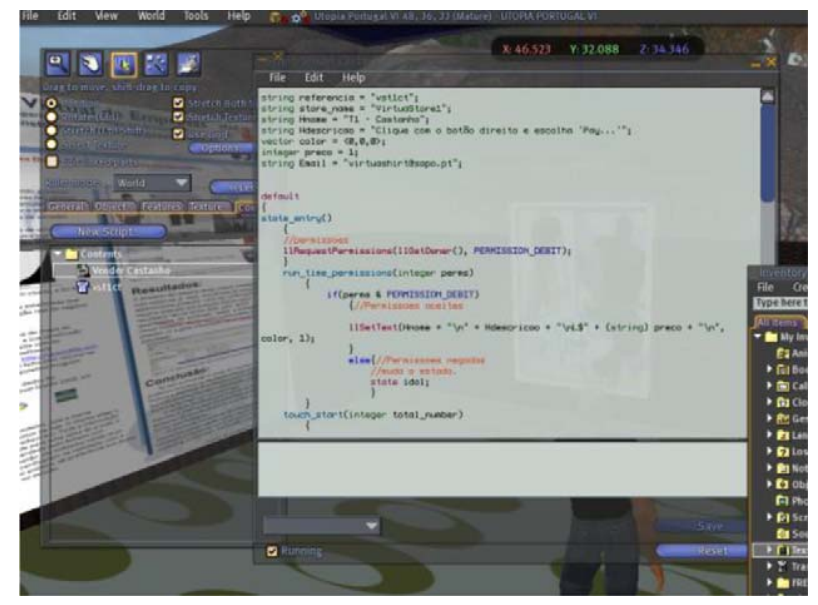

Figure 4. Linden Scripting Language script of the panels.

and brown), by physically observing them and holding them in his/her hand. To further enhance the distinction between physical and virtual versions, the physical t-shirts were not just plain t-shirts with different colours: their basic textile material had physical variations in texture and relief (identical for all t-shirts).
This was an actual purchase by each participant: to offset production costs, an actual price had to be paid.

\section{Results and discussion}

The empirical study was done with 57 participants selected as per convenience (each participant needed to have an avatar and geographical proximity regarding the researchers, so they could see and feel the physical product directly). The main objective was to collect data about the transactions made at the virtual store (the individuals' choice, when confronted with the three virtual t-shirt models in SL) and about the transaction of physical products. It must be stressed that consumers only saw the pictures presented in the boards of Figure 3 before making their "virtual" choice, i.e. they did not have the option to "try on" the t-shirt on the avatar before deciding, only after. They also only saw the physical t-shirt afterwards, not before.

Table 1 presents the data about SL user's preferences. It mentions three $\mathrm{t}$-shirt models. These are: white (t-shirt); black (t-shirt) and brown (t-shirt). The most popular model in this test was the black t-shirt, 


\begin{tabular}{|c|c|c|c|}
\hline & DE & ASSUNTO CONVERSA & DATA \\
\hline \multirow[t]{12}{*}{$凶$} & Virtua Shirt T1C & Venda: Filipe Merlin || Produto: vst1ct & 13:53:35 \\
\hline & Virtua Shirt T1B & Venda: FMiguel Pessoa || Produto: vst1br & $12: 37: 00$ \\
\hline & Virtua Shirt T1B & Venda: Gore Collas || Produto: vst1pr & $12: 32: 49$ \\
\hline & Virtua Shirt T1C & Venda: goblino Piek || Produto: vst1ct & $12: 22: 23$ \\
\hline & Virtua Shirt T1B & Venda: Flilipe Merlin || Produto: vst1pr & $12: 15: 15$ \\
\hline & Virtua Shirt T1B & Venda: Genius Bikcin || Produto: vst1br & 05:19:10 \\
\hline & Virtua Shirt T1C & Venda: Genius Bikcin || Produto: vst1ct & 05:18:39 \\
\hline & Virtua Shirt T1B & Venda: MFPantani Nootan || Produto: vst1pr & $17-06-2008$ \\
\hline & Virtua Shirt T1B & Venda: Misha Rau || Produto: vst1pr & 17-06-2008 \\
\hline & Virtua Shirt T1B & Venda: Misha Rau || Produto: vst1br & $17-06-2008$ \\
\hline & Virtua Shirt T1C & Venda: Lua Landar || Produto: vst1ct & $17-06-2008$ \\
\hline & Virtua Shirt T1B & Venda: Tarnura Galicia || Produto: vst1br & $17-06-2008$ \\
\hline \multicolumn{4}{|c|}{ - Venda: Filipe Merlin II Produto: vst1pr de Virtua Shirt T1B <1630ed61-03a9-1629-4462-915df60bec5c@|sl.secondlife.con } \\
\hline \multicolumn{4}{|c|}{$\begin{array}{l}\text { object-Name: Virtua Shirt T1B } \\
\text { Region: Utopia Portugal VI (290304, 306176) } \\
\text { Local-Position: }(51,48,34)\end{array}$} \\
\hline
\end{tabular}

Figure 5. Data log about avatar's preferences.

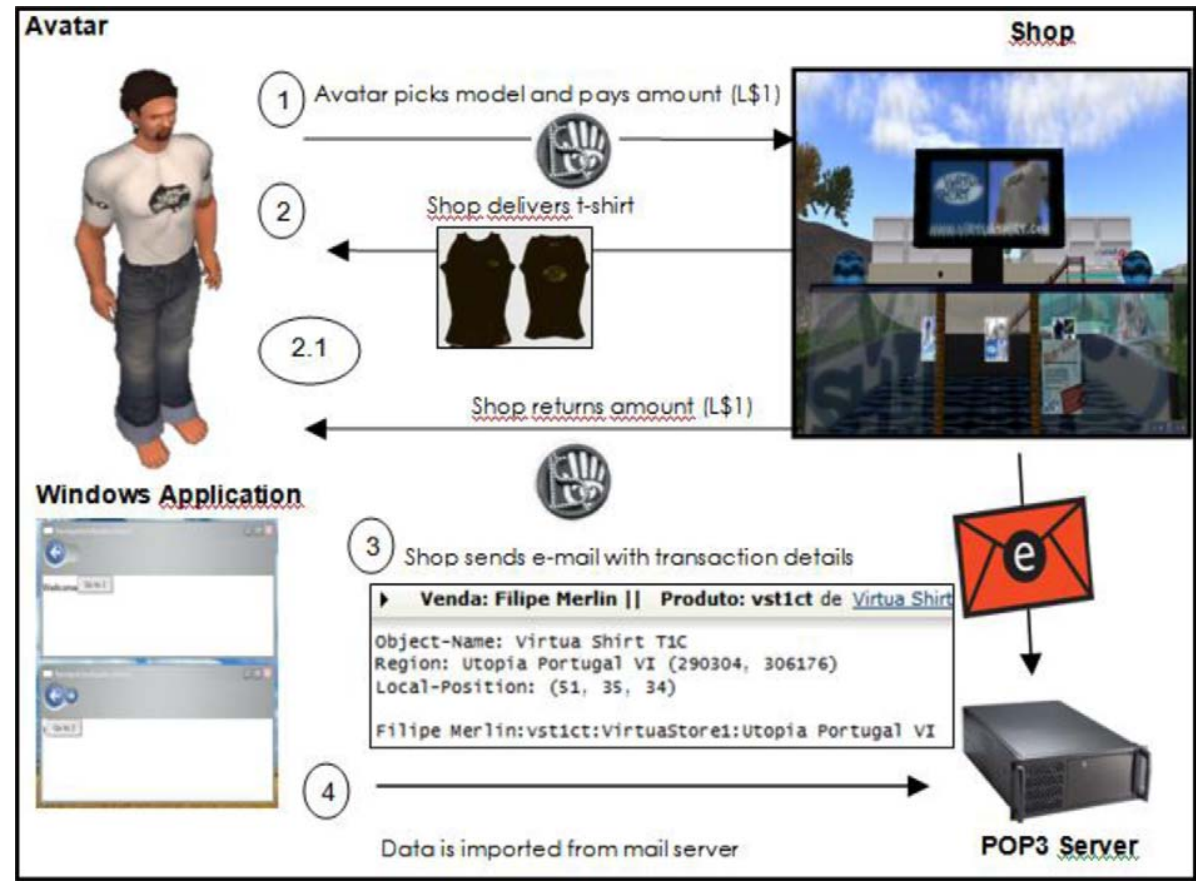

Figure 6. Process of the virtual test.

with 25 participants selecting it. This was particularly relevant in the case of male participants. In the case of female participants, the differences are not very significant, but that is not relevant for our test: we must stress that we are not looking at establishing preferences between models in this test (for that it would be important to have a larger sample), but at determining the level of matching between the virtual preferences and the physical preferences of the same buyers.

Regarding the actual sales of the physical t-shirts, only 48 of the 57 costumers of the virtual product chose to buy the physical product, i.e. about $84 \%$ of the initial participants. Thus, considering the preferences of the virtual t-shirts of these 48 buyers, we would expect to sell 21 of the black t-shirt, 12 of white t-shirt and 15 of the brown t-shirt. As we can see in Table 2, the actual sales for each physical t-shirt were 21 black, 10 white and 17 brown.

The test of selling the physical product follows the tendency of the virtual product: once again, the black model took the most choices. The similarity between the results of the two tests is an indicator that the participants' preferences are similar across the two versions of the product. In Table 3, one can find the results of a non-parametric correlation between SL preferences and physical preferences. As we can see, the Pearson correlation $(0.875)$ is significant at the 0.01 level.

Since we are analysing the same users, we can check specifically in which cases did the same 
Table 1. Crosstab gender $\times$ SL preferences.

\begin{tabular}{llcccc}
\hline \multirow{2}{*}{ Gender } & & \multicolumn{4}{c}{ SL preferences } \\
\cline { 3 - 6 } Male & Count & 11 & 19 & 11 & 41 \\
& White & Black & Brown & Total \\
& Within gender (\%) & 26.8 & 46.3 & 26.8 & 100.0 \\
& Within SL & 68.8 & 76.0 & 68.8 & 71.9 \\
& preferences (\%) & & & & \\
Female & Count & 5 & 6 & 5 & 16 \\
& Within gender (\%) & 31.2 & 37.5 & 31.2 & 100.0 \\
& Within SL & 31.2 & 24.0 & 31.2 & 28.1 \\
& preferences (\%) & & & & \\
Total & Count & 16 & 25 & 16 & 57 \\
& Within gender (\%) & 28.1 & 43.9 & 28.1 & 100.0 \\
& Within SL & 100.0 & 100.0 & 100.0 & 100.0 \\
& preferences (\%) & & & & \\
\hline
\end{tabular}

Table 2. Crosstab gender $\times$ physical preferences.

\begin{tabular}{llcccc}
\hline \multirow{2}{*}{ Gender } & & \multicolumn{4}{c}{ Physical preferences } \\
\cline { 3 - 6 } & & White & Black & Brown & Total \\
\hline \multirow{2}{*}{ Male } & Count & 8 & 15 & 13 & 36 \\
& Within gender (\%) & 22.2 & 41.7 & 36.1 & 100.0 \\
& Within physical & 80.0 & 71.4 & 76.5 & 75.0 \\
& preferences (\%) & & & & \\
Female & Count & 2 & 6 & 4 & 12 \\
& Within gender (\%) & 16.7 & 50.0 & 33.3 & 100.0 \\
& Within physical & 20.0 & 28.6 & 23.5 & 25.0 \\
& preferences (\%) & & & & \\
Total & Count & 10 & 21 & 17 & 48 \\
& Within gender (\%) & 20.8 & 43.8 & 35.4 & 100.0 \\
& Within physical & 100.0 & 100.0 & 100.0 & 100.0 \\
& preferences (\%) & & & & \\
\hline
\end{tabular}

Table 3. Correlation between SL preferences and physical preferences.

\begin{tabular}{lcc}
\hline & SL preferences & Physical preferences \\
\hline SL preferences & & \\
Pearson correlation & 1.000 & $.875^{* *}$ \\
Sig. (two-tailed) & & .000 \\
$N$ & 57.000 & 48 \\
& & \\
Physical preferences & & 1.000 \\
Pearson correlation & $.875^{* *}$ & \\
Sig. (two-tailed) & .000 & 48.000 \\
$N$ & 48 & \\
\hline
\end{tabular}

Note: ${ }^{* *}$ Correlation is significant at the 0.01 level (two-tailed).

individual buy the same t-shirt model (both virtual and physical), and in which cases did an individual change his/her preference upon seeing and holding the physical t-shirt. Only 4 of the 48 participants that took part on both studies made different choices, representing a coherence rate of $91.7 \%$.

\section{Conclusions and further work}

To summarize, we built a virtual store and created several virtual t-shirt models; collected the data regarding the preferences of the participants on the virtual models; manufactured the physical t-shirts (using the same models as the virtual t-shirts); collected the data regarding the sales of the physical models and studied the results. The virtual store prototype that was created for the experiences can be readily adaptable to many other types of industries and products.

One important question that we tried to answer was: can a product store in a virtual world provide valid results regarding user preference of physical products? Our exploratory study showed a very high coherence level for t-shirts, with about $91.7 \%$, so we can consider that at least for this specific kind of products SL should be considered quite seriously for conducting marketing studies of product prototypes. We believe that further studies should be conducted, with different populations, market segments and types of products. Also, further studies need to compare possible effects of "trying on" a t-shirt before buying (SL enables a product to have embedded computer code allowing it to be tested for a limited time before being destroyed or to have an associated "demo" sticker or tag, rendering it unusable except for trials, which would enable this line of inquiry). This will enable to better establish how to leverage this platform for market research of physical products. Specifically for the product analysed, it would be interesting to make a three-way comparison of user preferences between virtual $\mathrm{t}$-shirts, $\mathrm{t}$-shirts chosen through a traditional web page e-commerce site and physical t-shirts. I would be also interesting to run the same experiment under different conditions. For instance, with less common colours and/or with a more diversified set of participants. We also intend to conduct similar tests for other kinds of products.

\section{Acknowledgements}

We are grateful to Filipe Alves for the data gathering and for all support in the operacionalization of the experiment.

\section{References}

Aas, B.G. (2011). What's real? Presence, personality and identity in the real and online virtual world. In N. Zagalo, L. Morgado, \& A. Boa-Ventura (Eds.), Virtual worlds and metaverse platforms: New communication and identity paradigms (pp. 88-99). Hershey, PA: IGI Global.

Au, W.J. (2008, May 5). Second life marketing: Still strong, Figure 1 - user to user transactions. Business Week.

Bans, L. (2008). Same shit, different world. Bitch Magazine 39(Spring), 56-62.

Benetton, L. (2007, December 20). Virtual worlds. CBC News. 
Gorini, A., Gaggioli, A., Vigna, C., \& Riva, G. (2008). A Second Life for eHealth: Prospects for the use of 3-D virtual worlds in clinical psychology. Journal of Medical Internet Research, 10(3). Retrieved August 31, 2009, from http://www.pubmedcentral.nih.gov/articlerender. fcgi?artid=2553247

Johnson, L. (2008). Online virtual worlds: Applications and avatars in a user-generated medium. Testimony in the US House of Representatives. Retrieved August 21, 2009, from http://energycommerce.house.gov/images/stories/Documents/Hearings/PDF/110-ti-hrg.040108.Johnsontestimony.pdf

Neustaedter, C., \& Fedorovskaya, E. (2009). Presenting identity in a virtual world through avatar appearances. In Proceedings of Graphics Interface 2009 (pp. 183190). Toronto: Canadian Information Processing Society.

Nino, T. (2011). Second Life statistical charts. Retrieved September 30, 2011, from http://dwellonit.taterunino.net/ sl-statistical-charts/
Rehmeyer, J.J. (2007, June 23). Mapping a medusa: The Internet spreads its tentacles. Science News 171, 387388.

Scott, D.M. (2007, March). Marketing a Second Life. Econtent. Retrieved September 30, 2011, from http://www. econtentmag.com/Articles/Column/After-Thought/Marketing-a-Second-Life-19264.htm

Stewart, C. (2007, December 17). Second Life as a simulation tool. The Orange County Register.

Thilmany, J. (2008, October). Real-life business in Second Life. Mechanical Engineering, 64.

Valério, S., Pereira, J., Morgado, L., Mestre, P., Serôdio, C., \& Carvalho, F. (2009). Second Life information desk system using instant messaging and short messaging service technologies. In G. Rebolledo-Mendez, F. Liarokapis, \& S. Freitas (Eds.), IEEE First International Conference - games and virtual worlds for serious applicatios (pp. 125-132). Los Alamitos, CA: IEEE Computer Society. 